\title{
Exploratory Data Analytics to Study the Impact of Parameters to Enhance the Population of House Sparrow (Passer Domesticus).
}

Renukadevi. K

LDC: Lady Doak College

Merlynna Esther Maxmellion. P

LDC: Lady Doak College

Pitchumani Angayarkanni. S

LDC: Lady Doak College

Priyatharsini Rajendran ( $\nabla$ priyatharsinirajendran@ldc.edu.in )

LDC: Lady Doak College https://orcid.org/0000-0002-2903-1842

\section{Research Article}

Keywords: House Sparrow, Population, Kendall correlation, Cluster analysis, Principal Component Analysis, Exploratory data Analysis

Posted Date: November 30th, 2021

DOI: https://doi.org/10.21203/rs.3.rs-440060/v1

License: (c) (i) This work is licensed under a Creative Commons Attribution 4.0 International License. Read Full License 


\section{Abstract}

To achieve a sustainable conservation or adaptation strategy, it is necessary to understand the impacts of habitat and weather on particular species. Hence the study was focused to analyze the parameters that influence the population of house sparrow in various locations of Madurai Dist. Furthermore, its present and future suitable habitats have been predicted using computational tools. Statistical analysis and correlation were performed with data gathered through random sampling. Using correlation analysis, the association between various parameters was studied. Hierarchical clustering of data was performed by a Kendall Correlation coefficient to identify the suitable habitat and weather. Subsequently the Selection of the major parameters of a study was determined using Principal Component Analysis approach. The study highlights the significance of utilizing data mining and computational analysis to precisely understand the influence of various geographical parameters on the distribution and survival of the house sparrow population in an area. Based on the results obtained, abundance and distribution of house sparrow were closely related to the area of habitat in which house sparrows were found. The preference of particular habitat can be briefly explained using Kendall Correlation Matrix and cluster analysis. Using the Principal Component Analysis (PCA) technique, the population density of the house sparrow was studied. Taking these computational analyses into account will provide a new perspective on predicting the species distribution in the specific area thereby conserving it.

\section{Introduction}

House sparrow (Passer domesticus) plays a vital role in our ecosystem. Sparrows serve as an insect collector (pests) and helps in plant survival, they also act as an important agent for germination. They are abundantly found near the human habitats, like farms, suburban, and urban areas. The main food resources of house sparrow are the insects like caterpillar, grains, vegetables and fruits. They are uncommon in uninhabited woodlands, deserts, forests, and grasslands. Sparrows generally prefer smaller and confined places to construct nests, in man-made structures like rolling shop shutters (Balakrishnan .P et al. 2011; Nath et al. 2015), wall crevices of thatched roofs, electric pipelines, in ventilation holes and space available on the electricity meters as they are not exposed to the vagaries of nature, competitors and predators. (Ali 1996; Balaji et al. 2014). Though they are widespread, "State of India's Birds 2020" reported a gradual decline in the abundance of house sparrows, in urban areas.

\section{Population Studies:}

Fewer studies have been done on the observation and identification of house sparrow habitats. The standard methods of data collection for avian population studies are the 1. Point Count Method (Ralph et al. 1993), 2. Line Transect Method (Bibby et al. 1998). Point Counts Method was used to study the house sparrow population in 10 villages of Tiruchengode and Erode Taluks, Tamil Nadu, India from October 2017 to March 2018;wherein the study area was divided into grids of 1 sq.km and the population of house sparrow with respect to habitat structure and agricultural practice were analyzed (Deepalakshmi et al. 2019). Similarly, the population density of house sparrow in Moodbidri and Mijarfrom August 2016 to 
September 2016 was studied using point count method (SurajPrabhakar Naik 2016). The former method was used the study the population density of house sparrow in Virudhunagar District from December 2011 to December 2013 (Balaji et al. 2013). Generally, Point Count Method was used to compare the relative population of birds recorded in different sites. A sparrow survey was conducted in May 2007, using the Line Transect Method, with 18 transects, each of $50 \mathrm{~m}$ distance in different alleys of the township; wherein the abundance of the species was studied with respect to vegetation, nests, and number of houses, shops, and the characteristics of roofs, open areas, fencings, wells, and water pipes (Dhanya et al. 2010). The population pattern estimation in different localities was widely studied using Line Transect method and the Point Count method (Gavimath et al. 2016). The population data collection has also been done through eBird.org database, which has a collection of house sparrow distribution data from 2014 to 2018. In order to understand the reasons for the decline of the house sparrow, population study was widely conducted. Based on the population density studies, it was evident that the population of house sparrow was hugely dependent on the environmental parameters like the geographical location, vegetation, weather, food availability and nesting grounds(Mcgillivray Wb 1981; Shaw 2009; Sharma P et al. 2020). A decline in house sparrow population has been reported due to the absence of nesting sites within urban localities (Rajashekar and Venkatesha 2008). Similarly, It was claimed that monoculture farming could be a limiting factor for house sparrow nesting and breeding(Suraj Prabhakar Naik 2016). However, an increase in the sparrow population in urban localities with abandoned buildings was observed (Balaji et al. 2014). Several field studies have been carried out only to identify the various environmental parameters that influence the population density of the house sparrow, but the correlation of the specified parameter with the population density has been lacking. To date, no data were available on the status and habitat of House sparrow in the Madurai District. In the present study, an attempt has been made to correlate the impact of various environmental parameters on the population of house sparrow in various localities of this District and to stipulate a computational algorithm to predict the sparrow population given a specific parameter in an area. Using computational analytic tools, the reason for decline in house sparrow population could be identified and reversed with proper recovery strategies. Parameters which contribute to the prevalence of the house sparrow in a specified area were analyzed using Principal Component Analysis

\section{Methods}

\section{Study Area}

The area chosen for the present study was Madurai District; which is a popular destination for tourists and pilgrims in Tamil Nadu. It is one of the oldest and continuously inhabited cities of India. The geographical location of Madurai is $\sim 10 \mathrm{~N}, 78 \mathrm{E}$, with an average elevation of 101 meters. The study was undertaken for a period of 13 months, from Jan 2019 to Feb 2020. The district comprises of 13 blocks viz. Madurai East, Madurai West, Thirupparankundram, Melur, Kottampatti, Vadipatti, Alanganallur, Usilampatti, Chellampatti, T.Kallupatti, Sedapatti, Thirumangalam and Kallikudi comprising of 420 Village Panchayats [ $\left.{ }^{1}\right]$.The survey was carried out in all the 13 blocks of Madurai District represented in the 
Fig. ${ }^{2}\left[{ }^{2}\right]$. A total of 168 random places within the study area was surveyed, which comprised of urban, semi-urban and rural habitats.

Method of study: In the present study, population based monitoring method was adopted which involves point count stations at random across a geographic area or along roadways (Mark et al. 2000). As suggested by Hostetler et al. 2016, this method consists of standing in a specific point location and counting birds, recording the number of birds, nests or other relevant objects such as burrows, droppings and footprints, etc. The study was conducted for a stipulated period of 14 months from January 2019 to February 2020 in 168 study areas in Madurai Dist. In each study site, the population density of house sparrow was observed by standing in a circle of $20 \mathrm{~m}$ radius and counting the number of birds, nests, burrows, droppings and foot prints for 10 minutes. The observation was done from 08:00 $\mathrm{h}$ to 12:00 $\mathrm{h}$ and $15: 00 \mathrm{~h}$ to $17.30 \mathrm{~h}$ (IST). The study area was carefully observed and documented the presence of natural and artificial nesting sites, feeding grounds and other social activities of the sparrow.

Data Analysis: Data was analyzed using Microsoft Excel and QGIS (3.0.0) was used for a schematic representation of the maps. The population density of house sparrow observed through field survey was represented in the form of the Habitat patch area in Google map. The various parameters analyzed in the dataset include Block name, Day, Name of the Place, Status of House Sparrow, No. of Male, No. of Female, Weather and Habitat. The correlation between the number of male and the female sparrow population was done using scatter plot. The density and distribution of the male and the female sparrow population was analyzed with joint plot.To understand the distribution of data in the data set, Box plot was applied. The relation between the various parameters viz., status of house sparrow, number of male and female sparrow population density, weather and habitat were studied using correlation analysis. Since the collected dataset was ungrouped, hierarchical clustering analysis was performed to identify the similarities and differences within the studied parameters. The clustering correlation was analyzed using Kendall and Spearman technique; which is a rank-based correlation coefficient method. 


$$
\tau=\frac{\begin{array}{c}
\text { Kendall Correlation coefficient is determined using the formula } \\
\text { Number of concordant pairs }- \text { Number of discordant pairs }
\end{array}}{\mathbf{n}(\mathbf{n}-\mathbf{1}) / 2}
$$

- Concordant Pair: A pair of observations (x1, y1) and (x2, y2) that follows the property

$$
\begin{gathered}
\text { - } \mathrm{x} 1>\mathrm{x} 2 \text { and } \mathrm{y} 1>\mathrm{y} 2 \text { or } \\
\text { - } \mathrm{x} 1<\mathrm{x} 2 \text { and } \mathrm{y} 1<\mathrm{y} 2
\end{gathered}
$$

- Discordant Pair: A pair of observations (x1,y1) and (x2,y2) that follows the property

$$
\begin{gathered}
\text { - } \mathrm{x} 1>\mathrm{x} 2 \text { and } \mathrm{y} 1<\mathrm{y} 2 \text { or } \\
\text { - } \mathrm{x} 1<\mathrm{x} 2 \text { and } \mathrm{y} 1>\mathrm{y} 2
\end{gathered}
$$

- $\quad \mathbf{n}$ : Total number of samples

Note: The pair for which $\mathrm{x} 1=\mathrm{x} 2$ and $\mathrm{y} 1=\mathrm{y} 2$ are not classified as concordant or discordant and are ignored.

In order to validate the precision of the cluster groups, clustering algorithm was applied to the data points. The clustering algorithm assigns data points in a cluster such that the sum of the squared distance between the data points and the cluster's centroid (arithmetic mean of all the data points that belong to that cluster) is at the minimum. The lesser the variation within clusters, the more homogeneous (similar) the data points are within the same cluster. The Principal Component Analysis (PCA) technique was performed to the given data set of house sparrow population count to analyze the major factors or parameters which contribute to the prevalence of the house sparrow in a specified area. A feature selection method is proposed to select a subset of variables in principal component analysis that preserves as much information present in the complete data as possible. The information was measured by means of the percentage of consensus in the generalized Procrustes analysis.

\section{Results}

Population Density Prediction: Out of the 168 data collection points in Madurai District, the prevalence of house sparrow was observed in 109 study sites (Fig. 2).

Using Point count summary statistics, different assumptions about behavioral and population processes were reflected (i.e) Population mean abundance, maximum abundance, frequency and presence/absence (Matthew et al. 2005) .

In Fig. 3, the population density of house sparrow as observed by the point count method was represented with respect to the various parameters viz., Block, Date, Day, Place, Status of the house sparrow, Number of males, Number of female, Weather and Habitat. In all the 168 data collection sites, all the 10 parameters were recorded simultaneously to avoid statistical error during sampling. 
The number of male population against the female population in the study area was represented using Scatter plot, Joint Plot and Box Plot respectively (Fig. 4, 5 \& 6). In the Joint plot (Fig. 5), both the male and female population showed right-skewed distribution with outliers. The densest area of population distribution was in the range of -10 to 45 scale units.

Prediction of Habitat type Effect: The correlation matrix (Fig. 7) Indicates that the status of the house sparrow, no. of male, no. of female, weather and habitat are highly correlated with one another.

In Fig. 8 ,the cluster analysis of the obtained data set was represented, wherein the Kendall and Spearman correlation was employed to obtain clusters for the available data set. The Kendall and Spearman correlation is a rank-based correlation coefficient method. The Kendall Correlation Matrix illustrates the impact of various parameters on the population of house sparrow in the study area (Fig. 9).

Precision and Cluster Analysis : Based on the cluster analysis of the available data set, maximum data points were plotted using three clusters (Fig. 10). The influence of habitat and weather conditions on the house sparrow population was illustrated in Fig. 11.

Principal Component Analysis was performed on the available data set of house sparrow count to analyze the major factors or parameters which contribute to the population of the house sparrow in the study area

(Fig. 12).

\section{Discussion}

Using the population-based monitoring method, the observed population density indicates that it is apparent that the House sparrow was prevalent in damp weather compared to clear weather. The increase in the population of house sparrows during the North East monsoon season might be due to the availability of insect larva for its nestlings. Similarly, Rajashekar and Venkatesha 2008, has reported an increase in the number of birds during the South West monsoon (June-September) followed by the North-East monsoon (October-November) in Bangalore. Figures 4, 5 \& 6, represents the number of male population against the female population in the study area using Scatter plot, Joint Plot and Box Plot respectively. In the Joint plot (Fig. 5), both the male and female population showed right-skewed distribution with outliers. The densest area of population distribution was in the range of -10 to 45 scale units.The Boxplot (Fig. 6) Clearly illustrates the variation in the occurrence of male and female population between different study sites. This shows that the sampling was not similar, but extensively varied. The correlation matrix (Fig. 7) Indicates that the status of the house sparrow, no. of male, no. of female, weather and habitat are highly correlated with one another. Choudhary S et al. 2019, stated that habitat variables like the presence of old buildings, residential areas, vegetation, water, grocery shops, food provision, open drainage system and open household waste dump influenced the selection of habitat by house sparrows. The population of male and female house sparrow is highly correlated with one another; hence a decline in male population would be directly reflected in the occurrence of the female population and vice versa (Fig. 13). In the statistical interpretation (Fig. 14) it was evident that the number of male house sparrow was more than the female in a given location. Despite the statistical interpretation, it was 
scientifically proven that variation in the primary sex ratio in house sparrow population was potentially influenced by seasonal variation in parental quality where good quality mother were more likely to produce, when bred late in the breeding season (Trivers and Willard 1973).

Habitat plays a vital role in the survival of an organism. House sparrows have been spotted in both rural and urban habitats. In the present study, Fig. 15 illustrates the correlation between house sparrow population and the type of habitat (rural, semi urban and urban). Based on the above results it could be stated that the house sparrow population was more dominant in the rural habitat, followed by the semi urban habitat. A study emphasized that though sparrow showed least preference to urban habitats, the introduction of artificial nesting boxes could be a suitable measure to increase the house sparrow population in the urban habitat (Balaji et al. 2014).

The correlation between weather and population density of house sparrow in the study area was signified in Fig. 16,. The number of sparrows counted in sunny weather was 81 , while in clear and rainy weather conditions, the number of sparrows was 46 and 41 respectively. The data clearly show the preference of house sparrow towards sunny weather condition. Among the 13 study blocks surveyed in Madurai district, the maximum number of house sparrow count was recorded in Madurai West followed by Thiruparankundram, Madurai East, Thirumangalam, T.Kallupatti and Alanganallur (Fig. 17).

The average house sparrow count of the Madurai West block was 12.92. In the Kendall and Spearman correlation the endpoint was a set of clusters, where each cluster is distinct from other cluster, but broadly similar data are clustered together. The Kendall Correlation Matrix illustrates that the number of male, the number of female, status of house sparrow was found to be influenced by the habitat and weather of the study area. Based on the data points obtained from the cluster analysis, Cluster 0 , indicated that during clear weather, the male and female population count lies within 1-25 and were seen predominantly in rural areas compared to urban habitat. In Cluster 1, the data were grouped with reference to sunny weather, wherein the population count ranged from 1-35.Lastly in Cluster 3, rainy weather was taken into consideration, with the population ranging from 1-35. Performance evaluation of clustering indicated that a $100 \%$ precision and recall score was obtained and the data points correctly fall under the three clusters (Fig. 18).

Based on the computational analysis, the population of house sparrow in an area, was found to be directly influenced by the block location, habitat and weather conditions of the region. Hence, by further monitoring of these parameters, the decline in house sparrow population can be revived using suitable revocation strategies. Principle Component Analysis has selected five major features (Block, Habitat, Weather, No. of the female and No. of male) which plays a vital role in the prevalence of a house sparrow was explained in Fig. 12. Various studies were performed to obtain strong evidence that temperature, it acts as a cue for this plasticity in breeding timing, the exact nature of the cue and response remain unexplained. Matthysen et al. 2021 investigated that small-scale variation in egg laying date, explained by local tree phenology, tree species composition around its habitat. Hence such study can be 
incorporated for further clarification with response to species of trees and insect diversity with house sparrow population.

\section{Conclusion}

The study highlights the significance of utilizing data mining and computational analysis to precisely understand the influence of various geographical parameters on the distribution and survival of the house sparrow population in an area. Based on the Kendall Correlation Matrix and cluster analysis, the house sparrow population has been identified to prefer rural habitat. Using the Principal Component Analysis (PCA) technique, the major parameters influencing the population density of the house sparrow has been identified. The three important features or parameters which play a vital role in increasing the house sparrow population are block location; habitat and weather conditions of the area. By monitoring these parameters and providing ideal habitats, the declining number of house sparrows in other localities can be improved. The future perspective of computational analysis involves extensive data collection, such as architectural changes, agricultural practices, food availability, environmental factors and other bird diversity with reference to the surroundings of house sparrow by using habitat based point count method. Ecological modelling of house sparrow can be done through remote sensing and geographical imaging system too.

\section{Declarations}

\section{ACKNOWLEDGEMENTS}

Sincere thanks to Prof. Mrs. Lakshmi, Department of Physics, Lady Doak College for providing necessary guidance in GIS grid mapping of study sites.

Funding: The authors did not receive any research grants from any funding agencies for the submitted work.

Conflicts of interest/Competing interests: The authors have no conflicts of interest to declare that are relevant to the content of this article.

Availability of Data and Material: Not applicable.

Code availability: Not applicable.

Authors' contributions: All authors contributed to the study conception and design. Material preparation, data collection was done by Renukadevi.K and Merlynna Esther Maxmellion.P and analysis were performed by Pitchumani Angayarkanni.S The first draft of the manuscript was written by Renukadevi.K and the manuscript reviewing and editing were performed by Priyatharsini Rajendran, All authors contributed to the drafts and gave final approval for publications.

Ethics approval: Not applicable. 
Consent to participate: Not applicable.

Consent for publication: Not applicable.

\section{Websites}

1. https://madurai.nic.in/district-profile/

2.Madurai District map block wise: https://madurai.nic.in/administrative-setup/developmentadministration/\#villpan

\section{References}

1. Ali, S (1996) The book of Indian birds (1st ed). Oxford University Press, New Delhi

2. Balaji S (2014) Artificial nest box for house sparrow: An apt method to save the dwindling species in an urban environment.International Journal of Biodiversity and Conservation 6(3):194-198. doi:10.5897/IJBC2014.0689

3. Balaji S, Baskaran S, Rajan MK, Pavaraj M (2013) Investigation of the causes for the decline of house sparrow, Passer domesticus in Sivakasi Taluk, Virudhunagar District, Tamil Nadu, India. J. Pure Appl. Zool 1(2): 160-166

4. Balakrishnan P, Jijeesh N, Kurikkal MS, Maya T, Lijitha MP, Bhaskar RR, Vipeesh N (2011) Distribution, abundance and nest site characteristics of the house sparrow (Passer domesticus) in Manjeri municipality, Kerala [Technical report]. Wildlife Research and Conservation Trust. Manjeri, India, Kerala, India

5. Betts MG, Simon NPP, Nocera JJ (2005) Point count summary statistics differentially predict reproductive activity in bird-habitat relationship studies. J. Journal of Ornithology 146(2):151-159. doi:10.1007/s10336-005-0074-9

6. Bibby C, Jones M, Marsden S (1998) Expedition Field techniques: Bird Surveys. Royal Geographical Society, London

7. Choudhary S, Netrapal SC, Kalsi R (2019) Seasonal habitat selection by house sparrows across the urban matrix in Delhi, India. Journal of Wildlife and Biodiversity 3(4): 57-65. doi:10.22120/jwb.2019.113270.1084

8. Deepalakshmi S, AntilinSalomi A (2019) Impact of urbanization on House sparrow (Passer domesticus) diversity from Erode and Namakkal districts, Tamil nadu, India. Int. J. Adv. Res. Biol. Sci 6(11):22-27

9. Dhanya R, Azeez PA (2010) The House sparrow Passer domesticus Population of Arakku Township, Andhra Pradesh, India. Indian Birds 5(6):180-181

10. Gavimath L, Hosetti BB (2016) Trends in population density of house sparrow, Passer domesticus L. in Jamakhandi area in Bagalkot district. Karnataka, India. JRB 6(5):2062-2067 
11. Hostetler EM, Main MB (2016) Florida Monitoring Program: Point Count Method to Survey Birds. 10.13140/RG.2.1.4568.1049

12. Huff MH, Bettinger KA, Ferguson HL, Brown M, Altman B (2000) A habitat-based point-count protocol for terrestrial birds, emphasizing Washington and Oregon.Forest Service, Pacific Northwest Research Station,California

13. Matthysen E, Adriaensen F, Van de Kerckhove P, Vandekerkhove K (2021) Great and blue tit laying dates vary with fine-scale variation in local tree composition but not tree budburst. Journal of Ornithology. doi:10.1007/s10336-021-01872-2

14. McGillivray W. (1981). Climatic influences on productivity in the house sparrow. Wilson Bulletin 93 (2): $196-206$

15. Naik SP (2016) Rapid study of House Sparrows (Passer domesticus) in Moodbidri, Karnataka: Conference on Conservation and Sustainable Management of Ecologically Sensitive Regions in Western Ghats [The 10th Biennial Lake Conference]. Lake, UK 290-293

16. Nath A, Singha H, DebP, Das AK, Lahkar BP (2015) Nesting in a crowd: The response of house sparrow towards proximity to spatial cues in commercial zones of Guwahati city. Proceedings of the Zoological Society 69:249-254

17. Rajashekar S, Venkatesha MG (2008) Occurrence of house sparrow, Passer domesticus indicus in and around Bangalore. Current Science 94(4):446-49.

18. Ralph CJ, Geupel GR, Pyle P, Martin TE, DeSante DF (1993) Handbook of field methods for monitoring landbirds. Forest Service, Pacific Southwest Research Station, California

19. Sharma P, Binner M, Narwal G (2020) Population status and factors affecting abundance of house sparrow (Passer domesticus): A review. Bull. Env. Pharmacol. Life Sciences 9(5):120-124

20. Shaw M (2009) Investigating the role of socioeconomic status in determining urban habitat quality for the House Sparrow, Passer domesticus .Dissertation, University of Exeter.

21. Trivers RL, Willard D E (1973) Natural-selection of parental ability to vary sex-ratio of offspring. Science 179(4068):90-92. doi:10.1126/science.179.4068.90

\section{Figures}




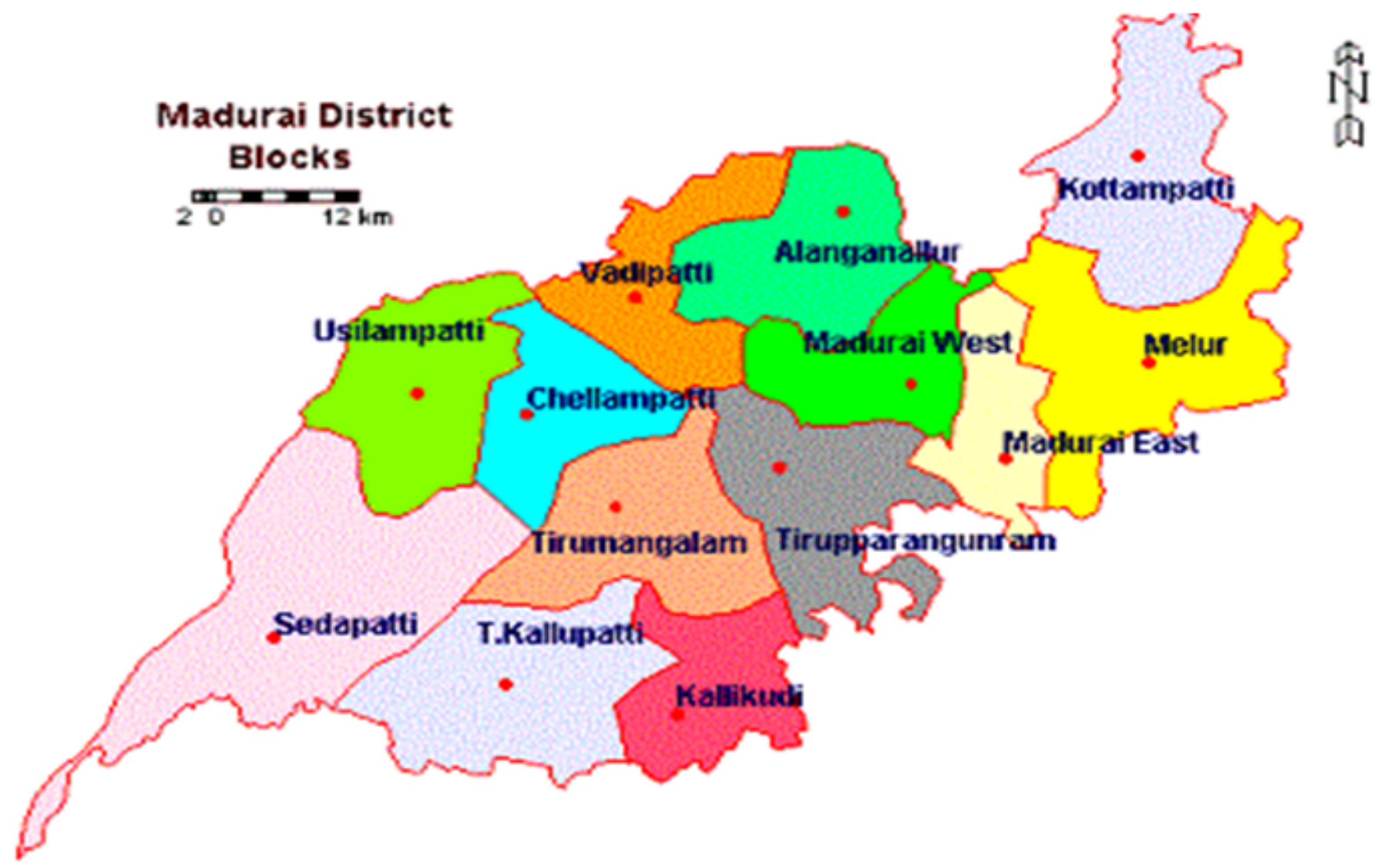

Figure 1

Block wise representation of the Madurai District

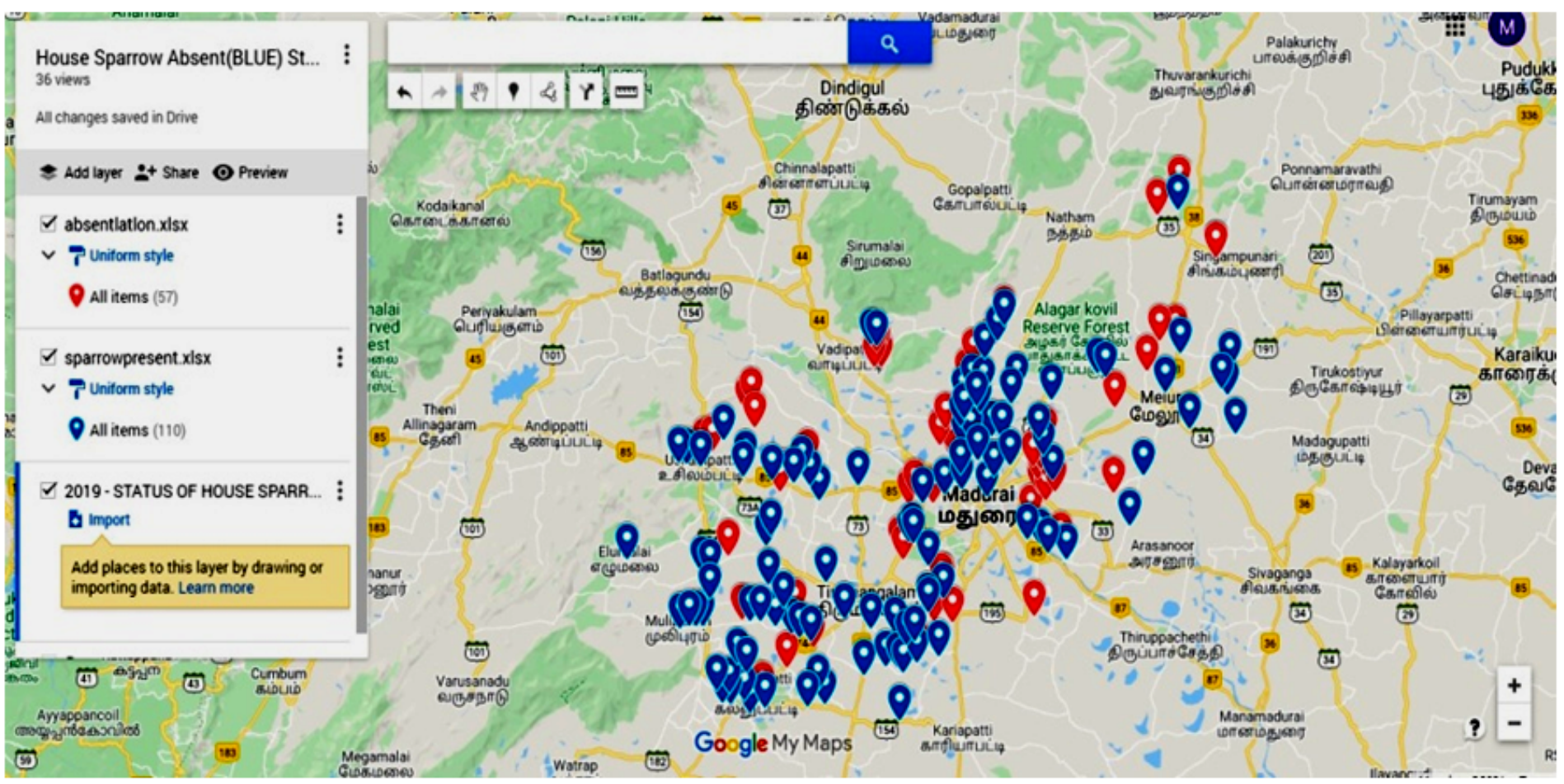

Figure 2 
Map of Madurai District illustrating the present (blue) and absent (red) sites of data collection Courtesy: Google Map

\begin{tabular}{|c|c|c|c|c|c|c|c|c|c|c|}
\hline & S.No & Block name & Date & Day & Name of the place & Status of House Sparrow & No.of. Male & No.of. Female & Weather & Habitate \\
\hline 0 & 1 & Madurai East & 25.2.2019 & Monday & Andarkottaram & Absent & 0 & 0 & Clear & Rural \\
\hline 1 & 2 & Madurai East & 25.2.2019 & Monday & Karseri & Absent & 0 & 0 & Clear & Rural \\
\hline 2 & 3 & Madurai East & 26.2.2019 & Tuesday & Ilandaikkulam & Absent & 0 & 0 & Clear & Rural \\
\hline 3 & 4 & Madurai East & 26.2 .2019 & Tuesday & Kalikappan & Absent & 0 & 0 & Clear & Rural \\
\hline 4 & 5 & Madurai East & 26.2.2019 & Tuesday & Ulaganeri & Absent & 0 & 0 & Clear & Rural \\
\hline$\cdots$ & $\ldots$ & $\ldots$ & $\ldots$ & $\ldots$ & $\ldots$ & $\ldots$ & $\ldots$ & $\cdots$ & $\ldots$ & $\ldots$ \\
\hline 163 & 166 & Kallikudi & 14.8.2019 & Wednesday & Thoombakulam & Present & 11 & 7 & Rainy & Rural \\
\hline 164 & 167 & Kallikudi & 14.8.2019 & Wednesday & Kallanai & Present & 14 & 13 & Rainy & Rural \\
\hline 165 & 168 & Kallikudi & 14.8.2019 & Wednesday & Nedungulam & Present & 34 & 24 & Rainy & Rural \\
\hline 166 & 169 & Kallikudi & 14.8.2019 & Wednesday & Periya ulagani & Present & 1 & 1 & Rainy & Rural \\
\hline 167 & 170 & Kallikudi & 14.8 .2019 & Wednesday & Koodakovil & Present & 2 & 1 & Rainy & Rural \\
\hline
\end{tabular}

168 rows $\times 10$ columns

\section{Figure 3}

Population density of house sparrow with respect to various parameters (168 study sites x 10 parameters)

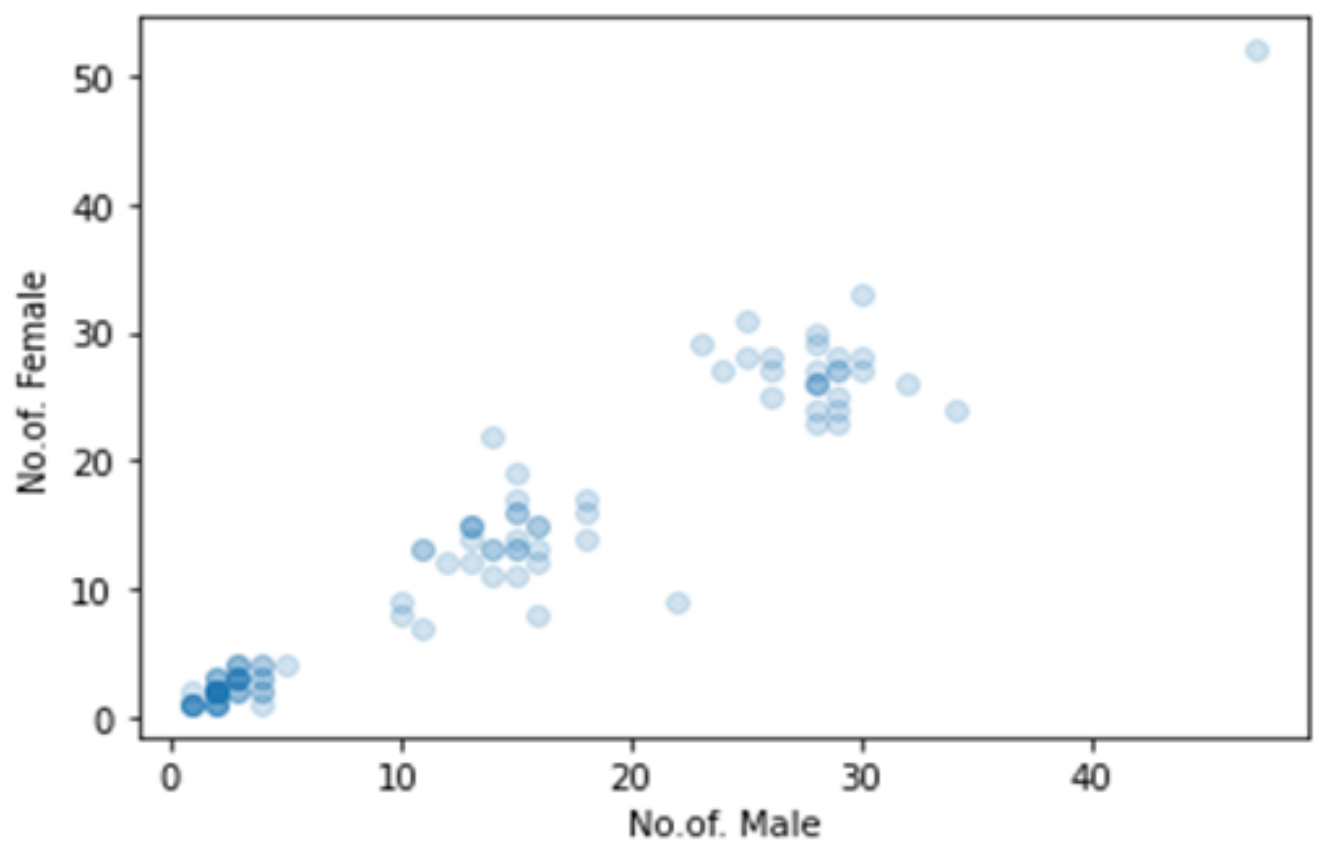

\section{Figure 4}

Scatter plot representing the correlation between the male and female population of house sparrow in the study area 


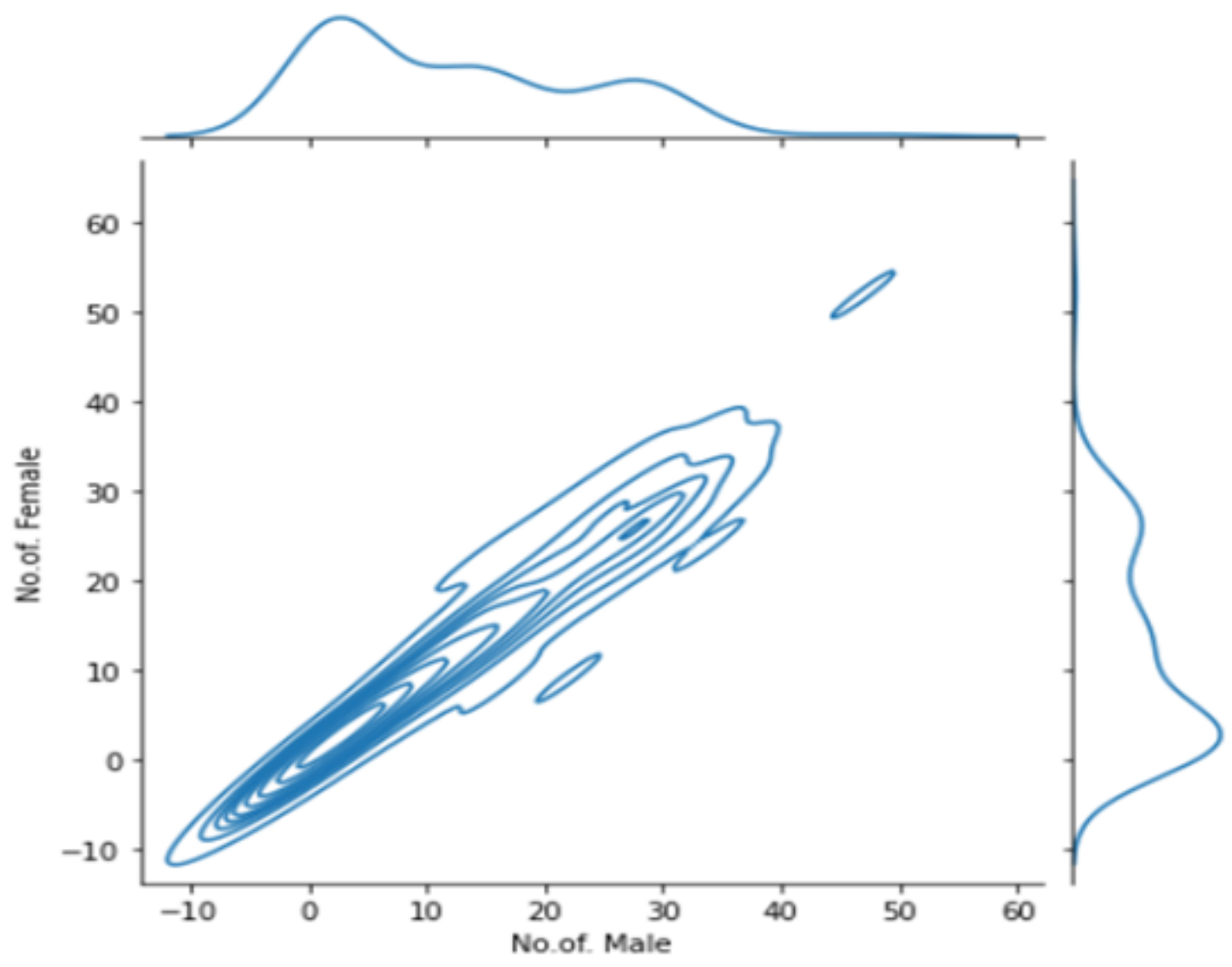

Figure 5

Joint plot representing the correlation between the male and female population of house sparrow in the study area

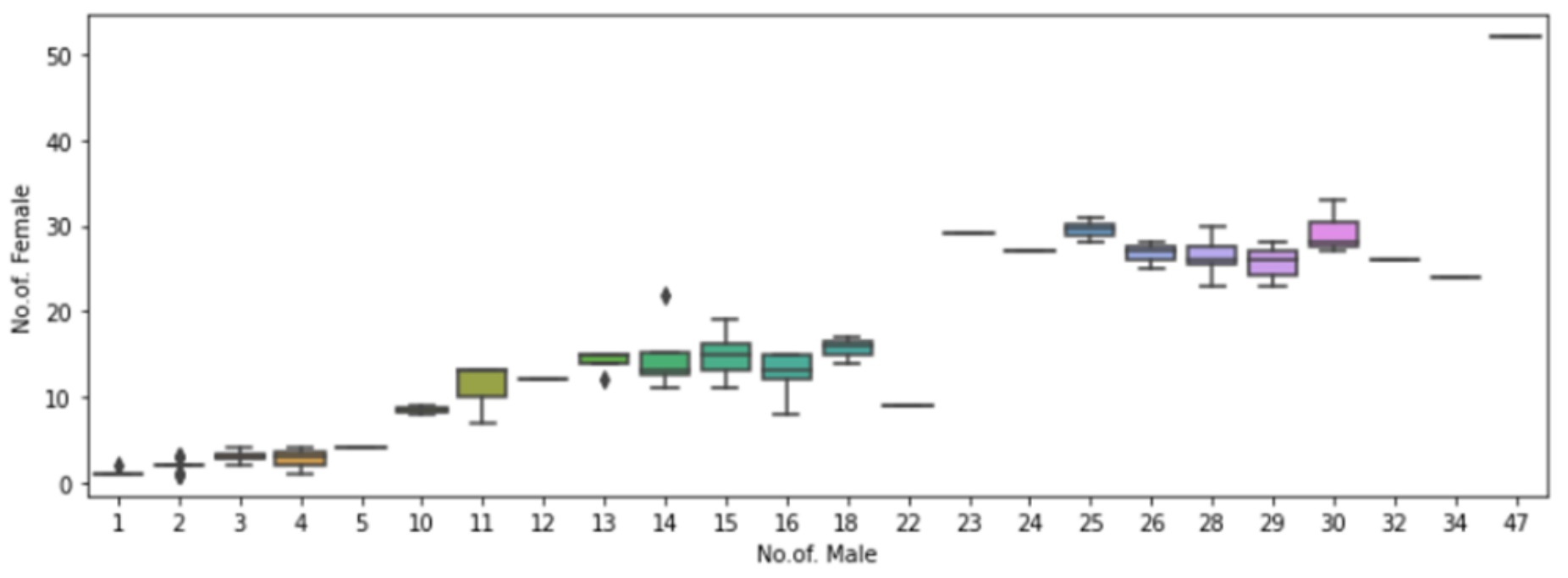

Figure 6

Box plot representing the correlation between the male and female population of house sparrow in the study area 


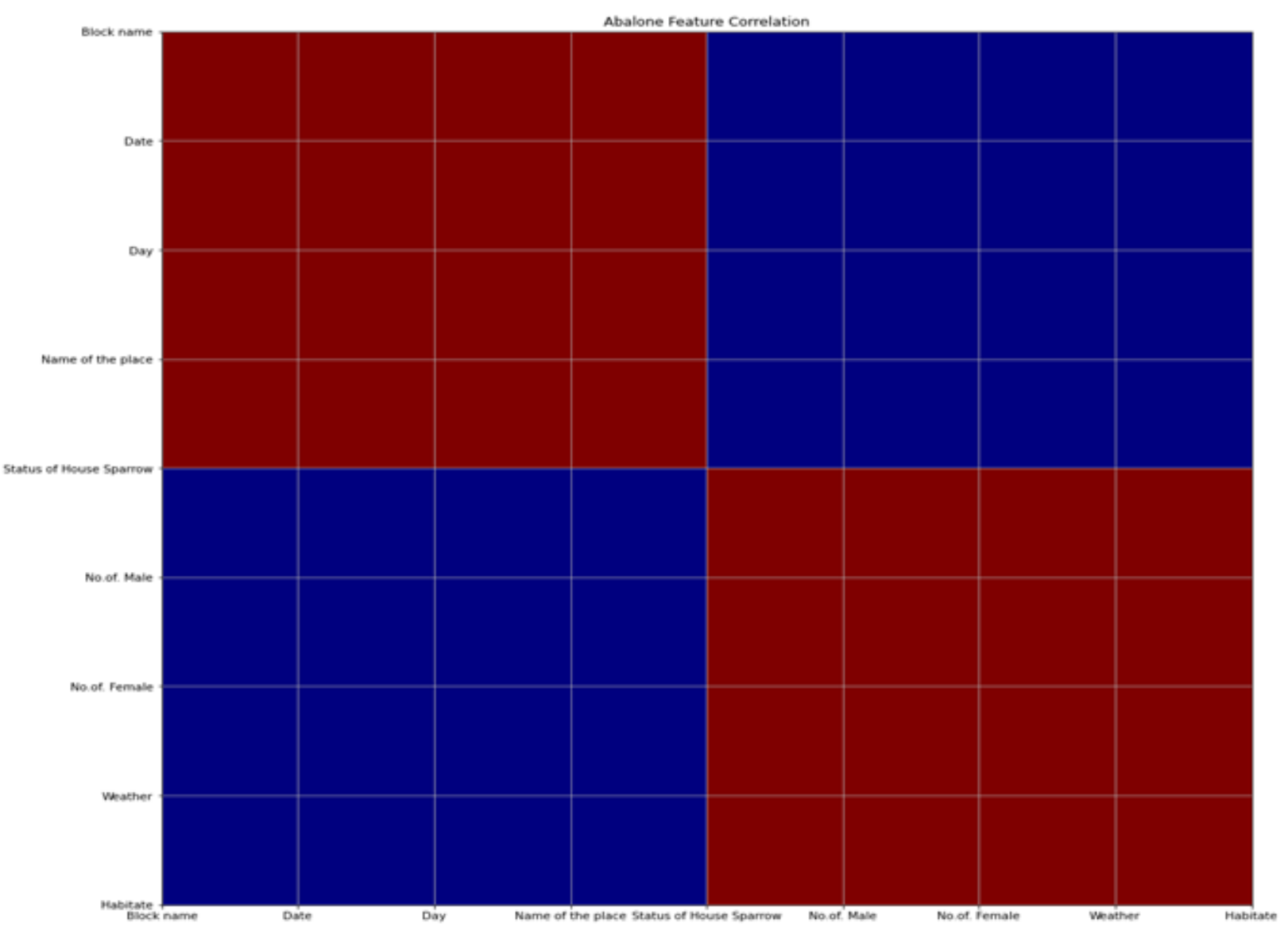

Figure 7

Correlation matrix of the various parameters (Block, Date, Day, Place, Status, Number of male, Number of female, Weather, and Habitat) influencing the population of house sparrow in the study area 


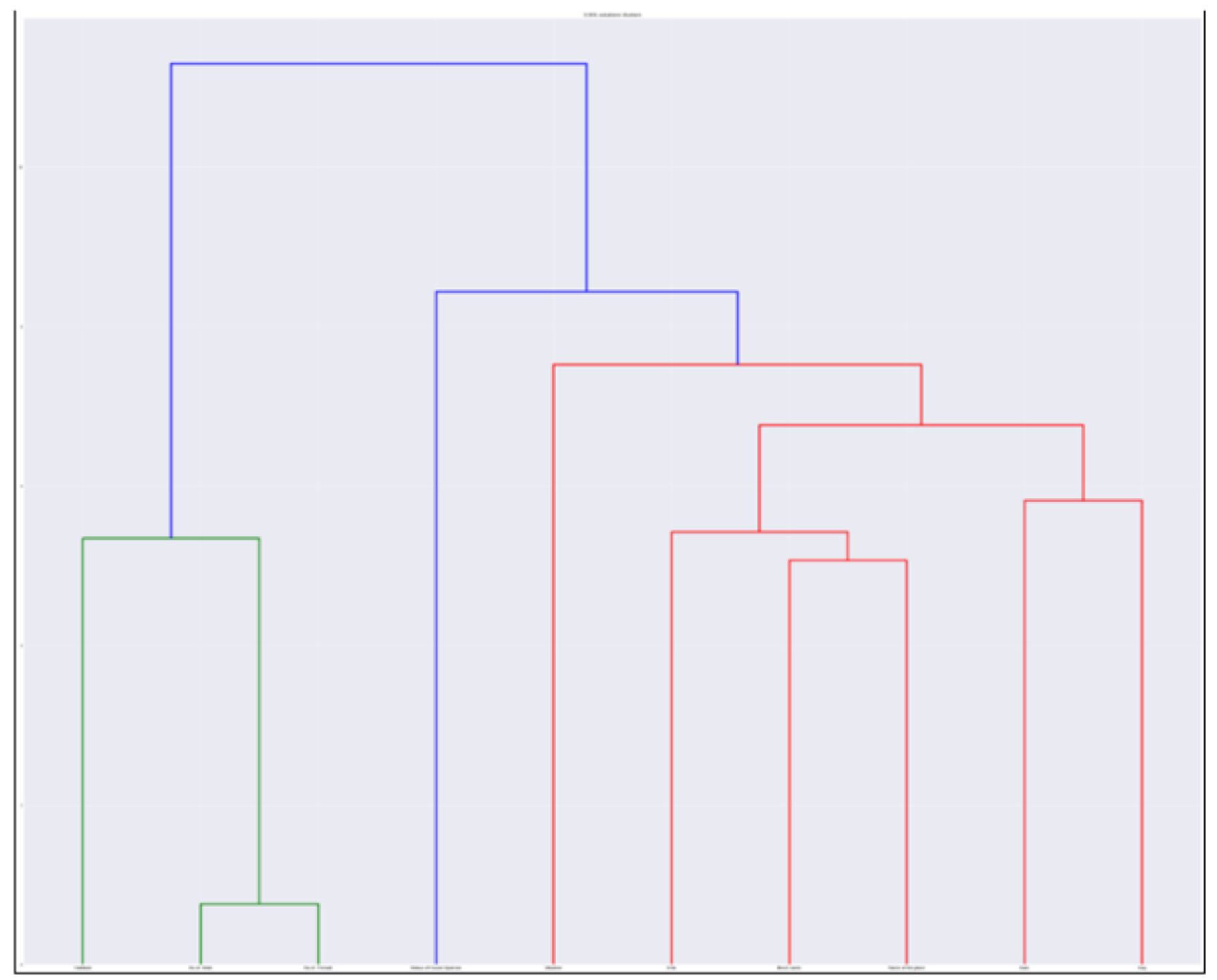

Figure 8

Cluster representation of the collected data with respect to the various parameters. (X-axis represents samples and $\mathrm{Y}$-axis represents the distance between these samples. There are 3 cluster solutions possible for the given dataset which is indicated by Blue, Green and red colours) 


\begin{tabular}{|c|c|c|c|c|c|c|c|c|c|c|c|}
\hline \multicolumn{11}{|c|}{ Kendall correlation of the 0.901 -solutions } & \multirow{2}{*}{10} \\
\hline Block name & 1000 & -0.327 & 0.005 & 0.080 & 0.023 & 0.011 & 0.001 & .0 .052 & 0.059 & -0.068 & \\
\hline Date & -0.327 & 1000 & -0.007 & -0.074 & -0.167 & -0.145 & -0.128 & -0.144 & 0.066 & -0.218 & 08 \\
\hline Day & 0.005 & -0.007 & 1000 & -0.034 & -0.070 & -0.101 & -0.107 & 0.025 & 0.182 & -0.119 & \\
\hline Name of the place & 0.080 & -0.074 & -0.034 & 1000 & 0.129 & 0.115 & 0.108 & 0.021 & 0.041 & -0.013 & \\
\hline Status of House Sparrow & 0.023 & -0.167 & -0.070 & 0.129 & 1000 & 0.732 & 0.731 & 0.098 & 0.125 & 0.151 & 0.4 \\
\hline No. of. Male & 0.011 & -0.145 & -0.101 & 0.115 & 0.732 & 1000 & 0.912 & 0.009 & 0.019 & 0.177 & \\
\hline No. of. Female & 0.001 & -0.128 & -0.107 & 0.108 & 0.731 & 0.912 & 1000 & 0.010 & 0.044 & 0.138 & \\
\hline Weather & 0.052 & -0.144 & 0.025 & 0.021 & 0.098 & 0.009 & 0.010 & 1000 & -0.118 & 0.142 & 00 \\
\hline Habitate & 0.059 & 0.066 & 0.182 & 0.041 & 0.125 & 0.019 & 0.044 & -0.118 & 1000 & -0.280 & \\
\hline duster & 0.068 & -0.218 & -0.119 & -0.013 & 0.151 & 0.177 & 0.138 & 0.142 & -0.280 & 1000 & \\
\hline & 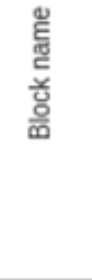 & జّ & 总 & 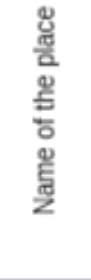 & 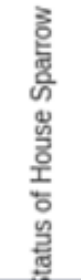 & 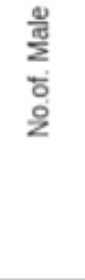 & 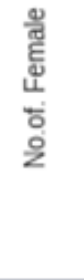 & 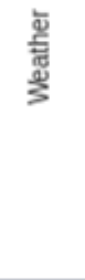 & 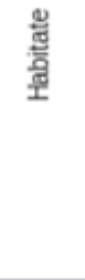 & $\begin{array}{l}\text { यू. } \\
\text { בे }\end{array}$ & \\
\hline
\end{tabular}

\section{Figure 9}

Kendall Correlation matrix of the various parameters (Block, Date, Day, Place, Status, Number of male, Number of female, Weather, and Habitat) influencing the population of house sparrow in the study area 


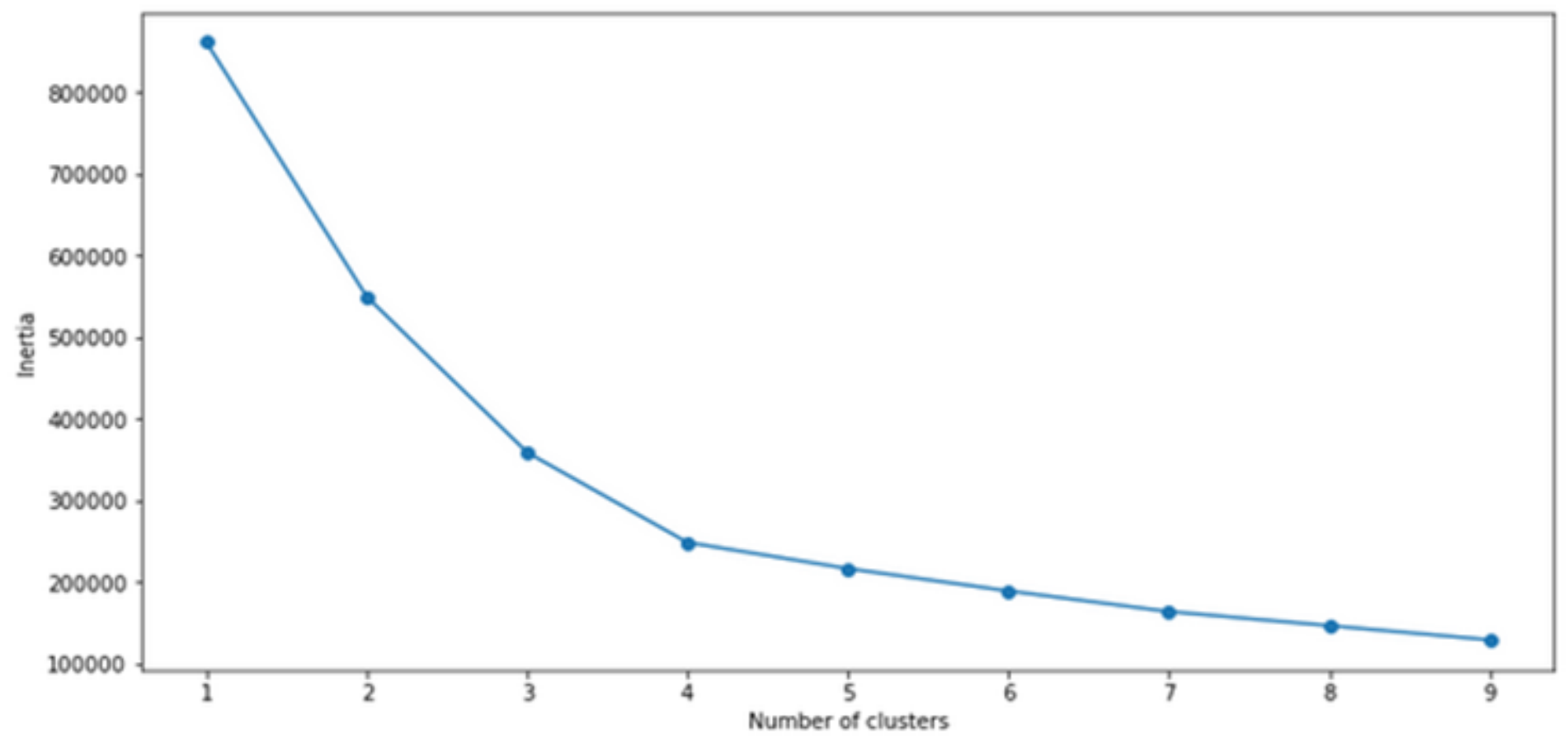

Figure 10

Cluster algorithm representing the number of clusters obtained from the available data

\section{Cluster Analysis}

175 Usual Distribution

- Priority Distribution

- Population Count

250

225

$\stackrel{\$}{\frac{5}{5}}^{100}$

so

25

0

o

25

so

${ }^{75}$ Habitate ${ }^{100}$

125

150

175

Figure 11 
Cluster analysis of the population density of the house sparrow with respect to weather and habitat in the study area

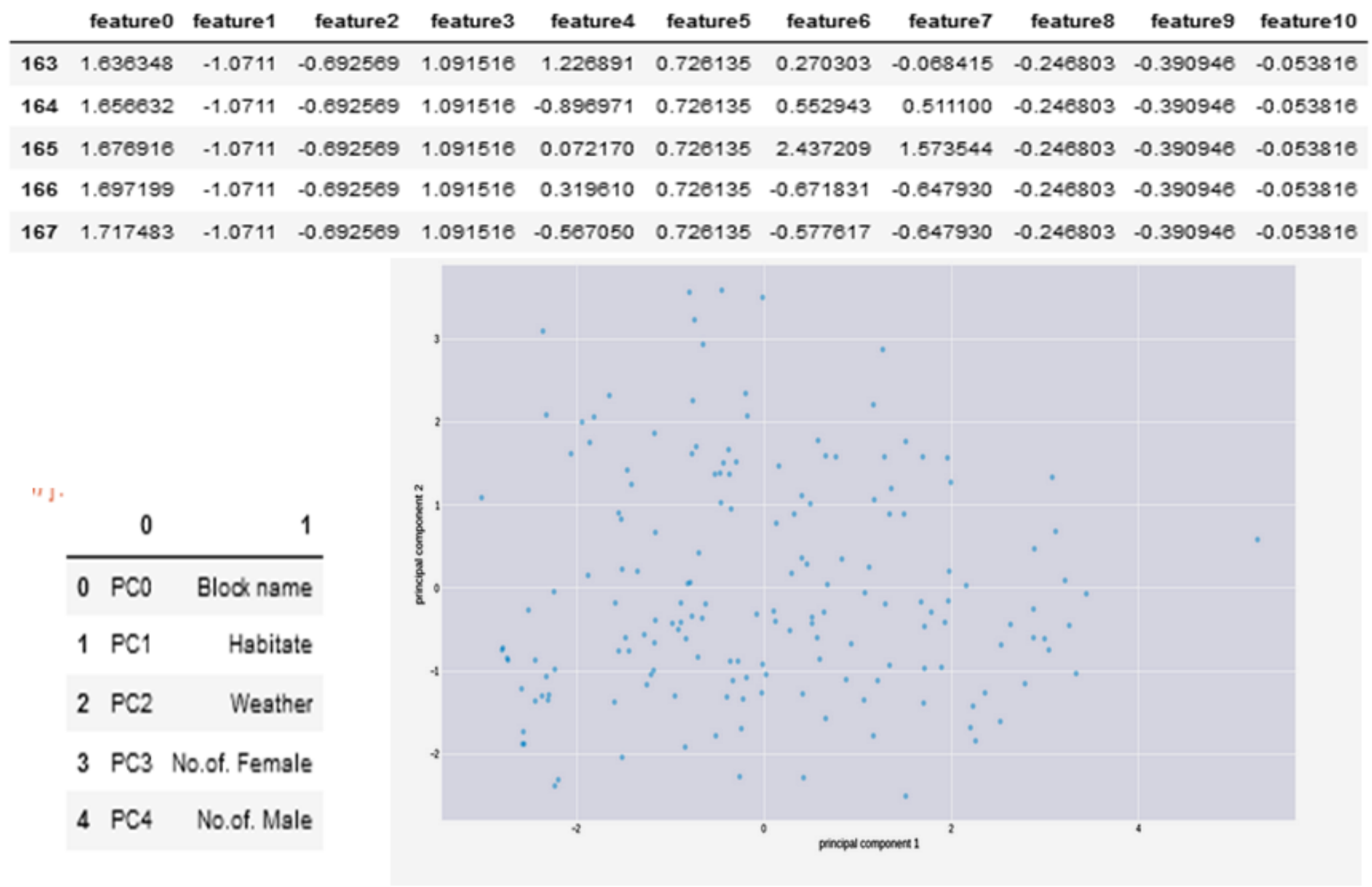

\section{Figure 12}

Principal Component Analysis (PCA) of the 10 parameters to choose the five major parameters influencing the population density of house sparrow in the study area 


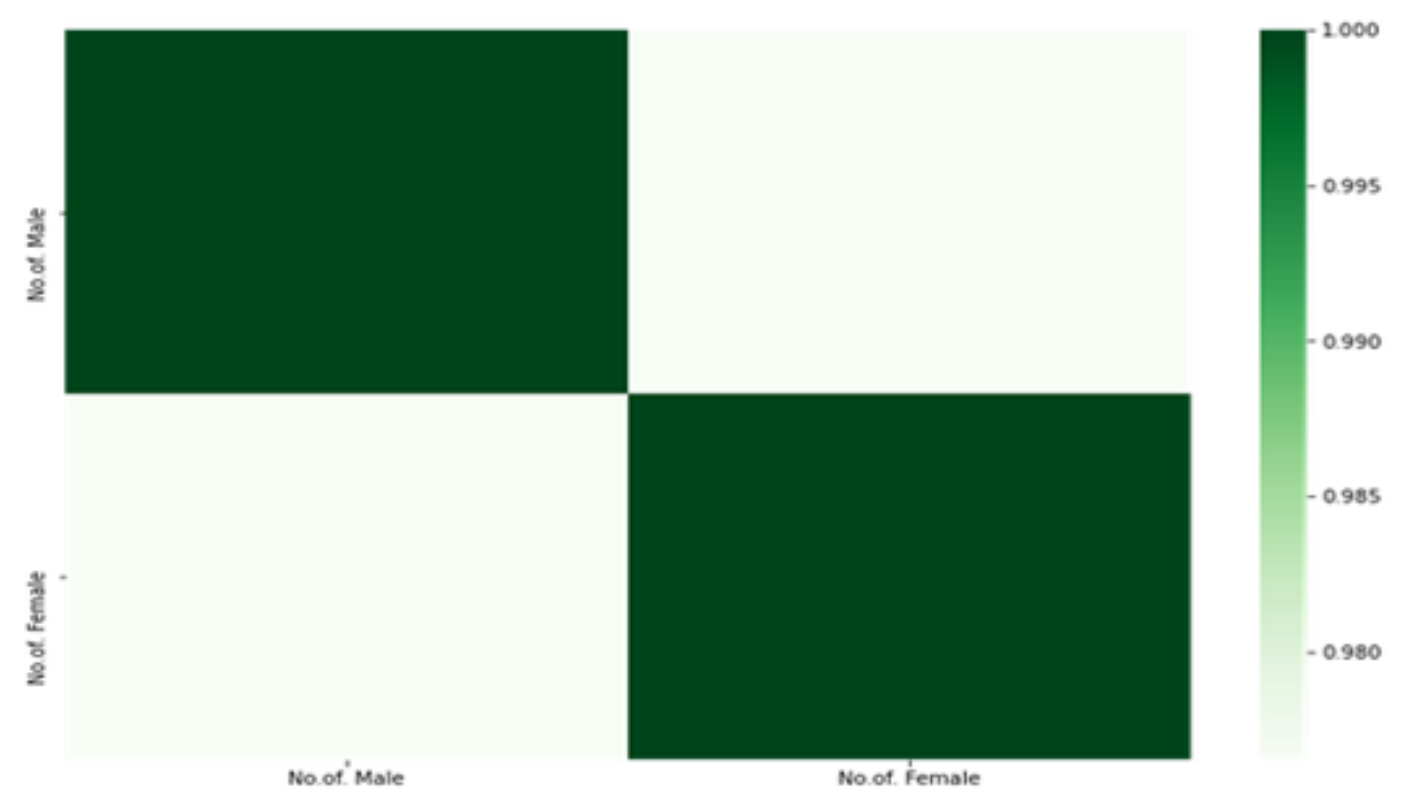

Figure 13

Correlation matrix between the male and female population of house sparrow in the study area

[11]:

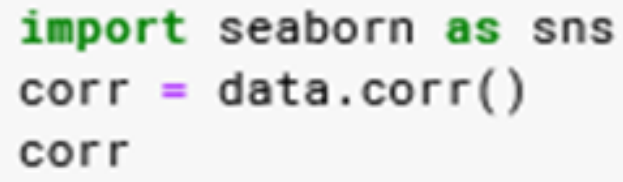

Out[11]:

\section{No.of. Male No.of. Female}

\begin{tabular}{rrr}
\hline No.of. Male & 1.000000 & 0.978558 \\
No.of. Female & 0.978558 & 1.000000
\end{tabular}

\section{Figure 14}

Statistical interpretation of the correlation between the population of male and female house sparrow in the study area 


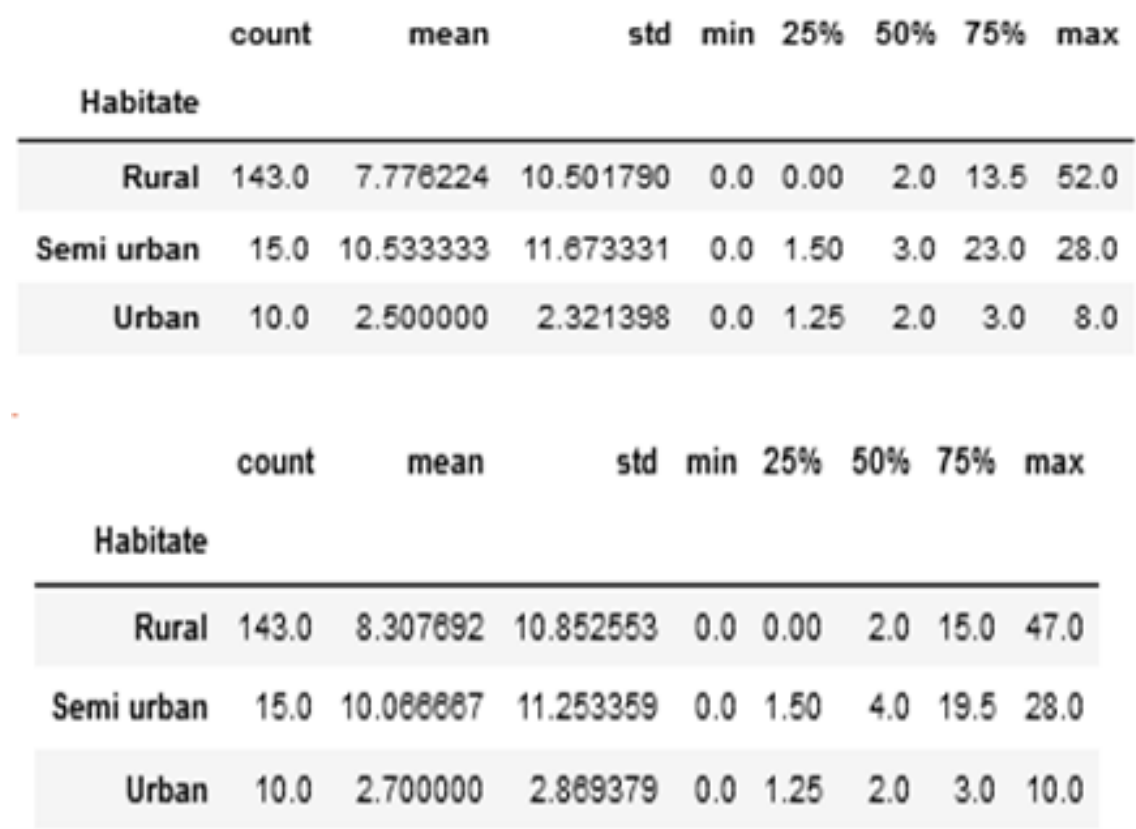

\section{Figure 15}

Statistical interpretation of the correlation between the population of house sparrow and the habitat (rural, semi urban and urban) in the study area

count mean std $\min 25 \% \quad 50 \% \quad 75 \%$ max

Weather

\begin{tabular}{rrrrrrrrr}
\hline Clear & 46.0 & 7.282609 & 10.847761 & 0.0 & 0.0 & 1.0 & 13.75 & 33.0 \\
Rainy & 41.0 & 10.146341 & 9.918571 & 0.0 & 1.0 & 9.0 & 17.00 & 29.0 \\
Sunny & 81.0 & 6.716049 & 10.275255 & 0.0 & 0.0 & 2.0 & 9.00 & 52.0
\end{tabular}

$\begin{array}{llllll}\text { count mean } & \text { std } \min 25 \% & 50 \% & \mathbf{7 5} \% & \max \end{array}$

Weather

$\begin{array}{lrrrrrrrr}\text { Clear } & 46.0 & 7.217391 & 10.605896 & 0.0 & 0.0 & 1.0 & 14.75 & 30.0 \\ \text { Rainy } & 41.0 & 11.385854 & 10.808841 & 0.0 & 1.0 & 12.0 & 18.00 & 34.0 \\ \text { Sunny } & 81.0 & 7.012346 & 10.383272 & 0.0 & 0.0 & 2.0 & 11.00 & 47.0\end{array}$

Figure 16

Statistical interpretation of the correlation between the population of house sparrow and the weather (clear, rainy and sunny) in the study area 


\begin{tabular}{|c|c|c|c|c|c|c|c|c|}
\hline \multirow[b]{2}{*}{ Block name } & count & mean & std & $\min$ & $25 \%$ & $50 \%$ & $75 \%$ & $\max$ \\
\hline & & & & & & & & \\
\hline Alanganallur & 14.0 & 4.928571 & 5.967402 & 0.0 & 0.00 & 3.0 & 10.50 & 16.0 \\
\hline Chellampatti & 12.0 & 13.583333 & 14.588030 & 0.0 & 0.00 & 8.0 & 27.75 & 33.0 \\
\hline Kallikudi & 12.0 & 9.083333 & 10.168418 & 0.0 & 1.00 & 4.5 & 15.50 & 26.0 \\
\hline Kottampatti & 10.0 & 4.000000 & 9.104334 & 0.0 & 0.00 & 0.0 & 0.75 & 28.0 \\
\hline Madurai East & 17.0 & 3.176471 & 6.511867 & 0.0 & 0.00 & 0.0 & 3.00 & 24.0 \\
\hline Madurai West & 18.0 & 6.722222 & 9.778762 & 0.0 & 1.25 & 2.5 & 4.00 & 28.0 \\
\hline Melur & 12.0 & 10.250000 & 15.731410 & 0.0 & 1.50 & 2.5 & 14.00 & 52.0 \\
\hline Sedapatti & 9.0 & 15.777778 & 10.509255 & 0.0 & 8.00 & 15.0 & 24.00 & 29.0 \\
\hline T. Kallupatti & 15.0 & 12.733333 & 10.109873 & 0.0 & 2.00 & 12.0 & 21.00 & 27.0 \\
\hline Thirumangalam & 16.0 & 5.062500 & 7.397916 & 0.0 & 1.00 & 2.0 & 5.25 & 26.0 \\
\hline Thiruparankundram & 18.0 & 5.111111 & 7.729918 & 0.0 & 0.00 & 1.5 & 10.50 & 26.0 \\
\hline Usilampatti & 8.0 & 8.000000 & 12.340410 & 0.0 & 0.00 & 0.5 & 12.75 & 28.0 \\
\hline Vadipatti & 7.0 & 6.571429 & 11.133390 & 0.0 & 0.00 & 0.0 & 8.50 & 29.0 \\
\hline
\end{tabular}

\begin{tabular}{|c|c|c|c|c|c|c|c|c|}
\hline \multirow[b]{2}{*}{ Block name } & count & mean & std & $\min$ & $25 \%$ & $50 \%$ & $75 \%$ & $\max$ \\
\hline & & & & & & & & \\
\hline Alanganallur & 14.0 & 5.214286 & 6.553667 & 0.0 & 0.00 & 2.0 & 11.50 & 16.0 \\
\hline Chellampatti & 12.0 & 12.833333 & 13.730082 & 0.0 & 0.00 & 7.5 & 28.00 & 30.0 \\
\hline Kallikudi & 12.0 & 11.750000 & 13.108810 & 0.0 & 1.75 & 6.5 & 17.75 & 34.0 \\
\hline Kottampatti & 10.0 & 4.100000 & 8.710785 & 0.0 & 0.00 & 0.0 & 0.75 & 25.0 \\
\hline Madurai East & 17.0 & 3.470588 & 7.151203 & 0.0 & 0.00 & 0.0 & 4.00 & 28.0 \\
\hline Madurai West & 18.0 & 6.686867 & 9.573247 & 0.0 & 1.25 & 3.0 & 3.75 & 26.0 \\
\hline Melur & 12.0 & 9.500000 & 14.761744 & 0.0 & 1.50 & 2.0 & 12.00 & 47.0 \\
\hline Sedapatti & 9.0 & 16.222222 & 10.022198 & 0.0 & 13.00 & 16.0 & 23.00 & 29.0 \\
\hline T. Kallupatti & 15.0 & 13.733333 & 11.151340 & 0.0 & 2.50 & 13.0 & 23.00 & 30.0 \\
\hline Thirumangalam & 16.0 & 6.750000 & 8.925619 & 0.0 & 1.00 & 3.0 & 7.00 & 28.0 \\
\hline Thiruparankundram & 18.0 & 5.168687 & 8.031189 & 0.0 & 0.00 & 1.5 & 9.00 & 28.0 \\
\hline Usilampatti & 8.0 & 8.000000 & 11.988089 & 0.0 & 0.00 & 0.5 & 13.50 & 29.0 \\
\hline Vadipatti & 7.0 & 6.714286 & 10.873734 & 0.0 & 0.00 & 0.0 & 9.50 & 28.0 \\
\hline
\end{tabular}

\section{Figure 17}

Statistical interpretation of the correlation between the population of house sparrow and the study blocks (Madurai East, Madurai West, Thirupparankundram, Melur, Kottampatti, Vadipatti, Alanganallur, Usilampatti, Chellampatti, T.Kallupatti, Sedapatti, Thirumangalam and Kallikudi) in Madurai Dist

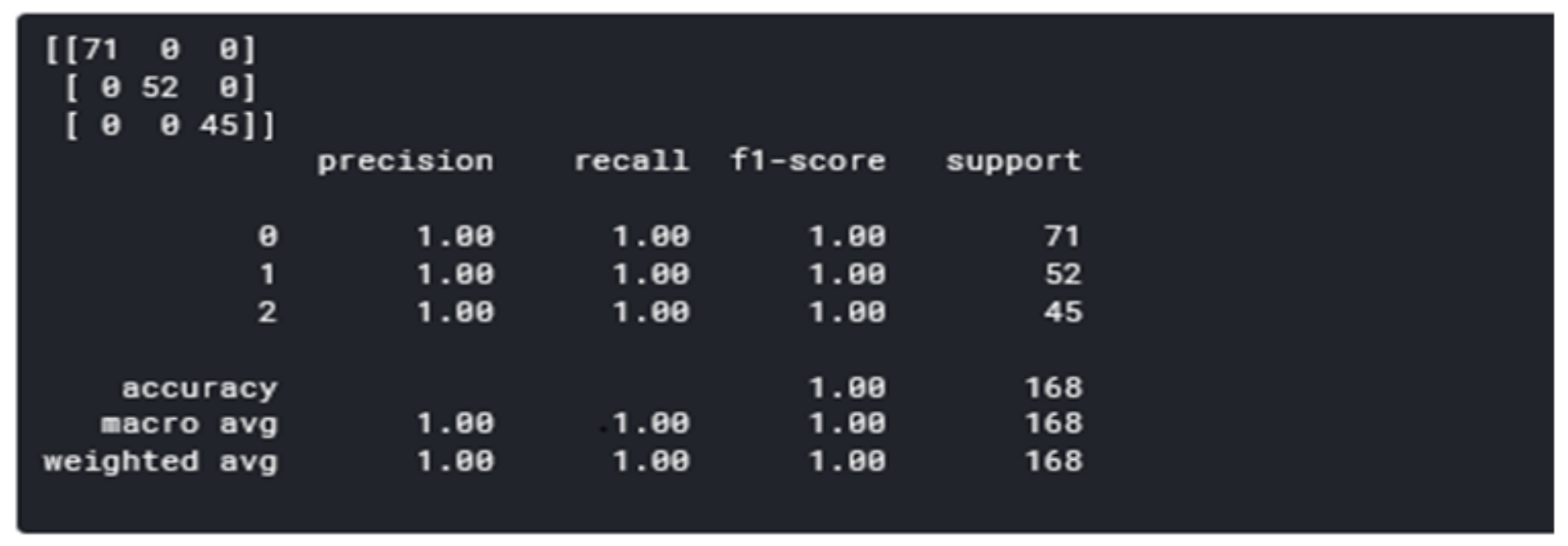

\section{Figure 18}

Precision analysis of the clustered groups obtained from the available data 